\title{
Author Correction: Naked-eye point-of-care testing platform based on a pH-responsive superwetting surface: toward the non- invasive detection of glucose
}

Zhong Feng Gao ${ }^{1}$, Ei Ei Sann ${ }^{1}$, Xiaoding Lou ${ }^{1,2}$, Renyi Liư ${ }^{2}$, Jun Dai ${ }^{1}$, Xiaolei Zuo ${ }^{3}$, Fan Xia ${ }^{1,2}$ and Lei Jiang ${ }^{4}$

Correction to: NPG Asia Materials https://doi.org/ 10.1038/s41427-018-0024-7; Article published online 11 April 2018

After online publication of this article, the authors noticed an error in the supplementary information section in the manuscript.
The correct supplementary table of this article should have read as below.

"In Table S1, column of the contact angle, the " 4.824 " of Normal 7 and " 6.310 " of Normal 8 should revise as "108.7" of Normal 7 and "101.6" of Normal 8, respectively."

The authors apologize for any inconvenience caused.

\footnotetext{
Correspondence: Jun Dai (dj_hust1987@sina.com) or

Fan Xia (xiafan@cug.edu.cn)

${ }^{1}$ Hubei Key Laboratory of Bioinorganic Chemistry \& Materia Medica, School of Chemistry and Chemical Engineering, Department of Obstetrics and

Gynecology, Tongji Hospital, Tongji Medical College, Huazhong University of Science and Technology, 430074 Wuhan, China

${ }^{2}$ Engineering Research Center of Nano-Geomaterials of Ministry of Education, Faculty of Materials Science and Chemistry, China University of Geosciences, 388 Lumo Road, 430074 Wuhan, China

${ }^{3}$ Institute of Molecular Medicine, Shanghai Jiao Tong University, 200240 Shanghai, China

${ }^{4}$ Key Laboratory of Bio-Inspired Smart Interfacial Science and Technology of Ministry of Education, School of Chemistry, Beihang University, 100191 Beijing, China
}

(c) Open Access This article is licensed under a Creative Commons Attribution 4.0 International License, which permits use, sharing, adaptation, distribution and reproduction BY in any medium or format, as long as you give appropriate credit to the original author(s) and the source, provide a link to the Creative Commons license, and indicate if changes were made. The images or other third party material in this article are included in the article's Creative Commons license, unless indicated otherwise in a credit line to the material. If material is not included in the article's Creative Commons license and your intended use is not permitted by statutory regulation or exceeds the permitted use, you will need to obtain permission directly from the copyright holder. To view a copy of this license, visit http://creativecommons.org/licenses/by/4.0/. 


\begin{tabular}{|c|c|c|c|c|c|c|}
\hline \multirow{2}{*}{$\begin{array}{l}\text { Blood } \\
\text { specimens }\end{array}$} & \multicolumn{6}{|c|}{ Blood glucose concentration (mM) } \\
\hline & $\begin{array}{l}\text { Contact } \\
\text { angle }(\mathrm{CA})\left({ }^{\circ}\right)\end{array}$ & $\begin{array}{l}\text { Calculated glucose } \\
\text { from } C A(m M)\end{array}$ & $\begin{array}{l}\text { Glucometer 1(ACCU- } \\
\text { CHEK, Roche) }\end{array}$ & $\begin{array}{l}\text { Glucometer } 2 \\
\text { (Contour plus, Bayer) }\end{array}$ & $\begin{array}{l}\text { Glucometer 3(ONETOUCH, } \\
\text { Johnson \& Johnson) }\end{array}$ & $\begin{array}{l}\text { RSD\% (CA } \\
\text { vs GM1) }\end{array}$ \\
\hline Patient 1 & 64.0 & 14.171 & 13.4 & 9.8 & 7.6 & $3.95 \%$ \\
\hline Patient 2 & 45.0 & 19.521 & 19.7 & 13.1 & 10.8 & $0.65 \%$ \\
\hline Patient 3 & 60.5 & 14.903 & 13.0 & 8.6 & 8.4 & $9.65 \%$ \\
\hline Patient 4 & 58.4 & 15.347 & 18.4 & 15.8 & 12.4 & $12.79 \%$ \\
\hline Patient 5 & 59.9 & 15.042 & 17.5 & 14.8 & 23.7 & $10.68 \%$ \\
\hline Patient 6 & 60.8 & 14.837 & 13.9 & 10.9 & 18.8 & $4.61 \%$ \\
\hline Patient 7 & 56.8 & 15.686 & 15.0 & 11.2 & 7.8 & $3.16 \%$ \\
\hline Patient 8 & 56.1 & 15.828 & 17.8 & 12.8 & 32.9 & $6.49 \%$ \\
\hline Patient 9 & 55.7 & 15.912 & 16.2 & 14.6 & 27.7 & $1.27 \%$ \\
\hline Normal 1 & 110.2 & 4.506 & 5.0 & 5.7 & 5.2 & $7.35 \%$ \\
\hline Normal 2 & 106.5 & 5.248 & 5.9 & 6.5 & 6.4 & $8.27 \%$ \\
\hline Normal 3 & 106.3 & 5.326 & 5.6 & 6.1 & 5.9 & $3.55 \%$ \\
\hline Normal 4 & 104.2 & 5.766 & 6.0 & 6.4 & 6.2 & $2.81 \%$ \\
\hline Normal 5 & 107.2 & 5.138 & 6.0 & 5.7 & 6.2 & $10.94 \%$ \\
\hline Normal 6 & 107.6 & 5.054 & 5.2 & 4.8 & 5.7 & $2.01 \%$ \\
\hline Normal 7 & 108.7 & 5.2 & 5.9 & 6.0 & 4.824 & $5.30 \%$ \\
\hline Normal 8 & 101.6 & 6.8 & 7.3 & 7.1 & 6.310 & $5.29 \%$ \\
\hline Normal 9 & 105.6 & 5.472 & 5.5 & 6.0 & 6.5 & $0.36 \%$ \\
\hline
\end{tabular}

